\title{
ENVIRONMENTAL ASSESSMENT ORGANIZATION BY USING A COMBINED APPROACH OF FUZZY AHP AND SWOT ANALYSIS CASE STUDY: HEALTH NETWORK OF KASHAN UNIVERSITY OF MEDICAL SCIENCE
}

\author{
Meghdad Rahati \\ Kashan University of medical Sciences, Kashan, I.R. Iran \\ mrahati90@yahoo.com \\ Masoud Dehghani \\ Kashan University of medical Sciences, Kashan, I.R. Iran \\ Reza Razzaghi \\ Department of Infectious Disease, Medical Faculty, Kashan University of medical Sciences, \\ Kashan, I.R. Iran \\ Rezarazzaghi33@yahoo.com \\ Reza Nanakar \\ Kashan University of medical Sciences, Kashan, I.R. Iran \\ rnanakar@yahoo.com \\ Zahra Sakeni \\ Kashan University of medical Sciences, Kashan, I.R. Iran \\ Z sakeni@yahoo.com \\ Abas Kavosian \\ Kashan University of medical Sciences, Kashan, I.R. Iran \\ Zahra Hashemi Dehaghi \\ Eye Research Center, Tehran University of Medical Sciences, Tehran, Iran \\ Hashemi_mitra@yahoo.com
}

\begin{abstract}
Today's, one of the secrets to success in organizations is power of analysis. Analysis of strengths, weaknesses, opportunities and threats is an appropriate tools. As regards the importance of each above factors is equal in prioritizing and decision making, in this study, researchers had certain importance and weight of each factors quantitatively with combined approach of Fuzzy AHP and SWOT Analysis. In this applicable, cross-sectional and descriptive study, that had been done in Health Network of Kashan University of Medical science, were used three questionnaires for data collection and was conducted during the four steps: 1.Identification environmental factors 2. Measurement environmental factors (main criteria) 3 . Calculate the Weight of sub criteria (Level two) 4. Finalizing weight of each factor. In the ranking of environmental factors, Fuzzy AHP method has been used. In this study between environmental factors, Weaknesses, had highest weight. Also in analysis of environmental Health Network, Weaknesses in finance management (0/131) and appropriate distribution of age and education level of employment experts $(0 / 085)$ had highest priority rank. In analysis of environmental factors by using a combined approach of Fuzzy AHP and SWOT Analysis ,by giving weight and degree in internal and external factors, can be obtain more precise results than SWOT method.
\end{abstract}


Keywords: Fuzzy hierarchical analysis, SWOT analysis, synthesis models SWOT

\section{INTRODUCTION}

Today, health systems are one of the largest sectors of the world economy and global costs of health care make up about 8 percent of GDP. This figure is about 5 to 10 percent in developing countries. (In Iran, more than $6 / 4 \%$ of GDP is allocated to the health sector costs) [1].Rapid increase in health care costs to the extent that main problem is how to control costs of health care systems in different countries, even rich countries of the world [2]

International organizations that are working to improve the health of all the world's countries (such as the World Health Organization and the World Bank) believe what most threatens health in developing countries, there are problems in the resources management, no shortage of health budget [3] So there is wide perspective for enhance and improve these resources management and Full attention to performance of it has particularly important [1] [4] So in this context we need effectively and efficiently methods. Methods that evaluate performance base on job description and certain criteria, identify strengths and weaknesses performance and with correction function improve quality of service [5].

From development perspective, performance assessment is an integral part of management system. The lack of organization assessment, is assigned as one of the symptoms of disease [6] . The results of evaluation can inform managers from the rate of activities, programs and objectives progress; which causes to identified strengths and weaknesses, and with emphasis on extend and empowerment strengths, resolve failures [7] . Performance evaluation system should be designed to arouse employees for performance improvement, participation in efficiency, effectiveness and excellence organization [8].

Today also, competition for improve quality service is known as a key strategic issue for organizations that are active in the service sector. Organizations that achieve a higher level of quality service, will have higher levels of customer satisfaction as a prelude to achieving sustainable competitive advantage [9].No doubt make satisfactory in customer and even delighted his for quality service, in the first step, requires to understanding their needs and desires and then transfer it to a situation that products and services are produced. This is due to increasing complexity of economic, social and cultural systems, not occur spontaneously, rather requires systematic methods and procedures as these concepts convert to organizational process [10].

In this regard, in health system, most managers and politicians has been used various evaluation and control models and quality improvement for promoting and increasing clients satisfaction. Today as regards technological advances, growing expectations of customer, increasing demand, lack of resources, increasing competition, as well as there are concerns about safety, malpractice and errors in health care system, has caused much emphasize strict assessing and evaluating performance in health care organizations [11].

Obviously, appropriate use of capacity health sector requires study and careful planning. Indeed, a comprehensive and integrated program that can determine position and current status of this sector and provide appropriate solutions and strategies for achieving desired status appears to be necessary. So in this study had been investigated strengths, weaknesses, opportunities and threats that exist in the health sector by using a combined approach of Fuzzy AHP and SWOT Analysis.

\section{MATERIAL \& METHOD}

This research is applied, descriptive and cross- sectional study which was done in 2014. 
Necessary data for this study were collected by using three questionnaires and during four stages as follows:

\section{Phase I: Identification environmental factors}

At this stage, questionnaire number one with combination of open and closed questions (containing 118 questions) prepared and was distributed among the first population including the chairman, deputies, managers and all of staff and line responsible expert (total 42). The questions are designed in two parts. The first part of the question related to internal environment in the areas of management, labor, organizational structure, work processes, organizational culture, financial management, management information systems and second part related to external environment in the field of economic, political, social and technological, that ultimately lead to identification internal factors (strengths, weaknesses) and external (opportunities and threats) which influencing strategic decisions of organization.

\section{Phase II: Measurement environmental factors (main criteria)}

In this step in order to calculate weight of four criteria (strengths, weaknesses, opportunities and threats) were designed questionnaires number two. This questionnaire had been prepared by method of hierarchical fuzzy, which based on SAATY scale and paired comparisons. In this method, paired comparison of criteria in each level is according to criteria of higher level. Decision-makers for comparison based on fuzzy AHP model used oral judgment. Be assigned numerical values to oral judgments, regarding the importance of each variable, and had been identified most important variables. Number of comparisons is equal $n(n-1) / 2$, that is according to the four criteria, the number of comparisons or questions is equal to six. As can be seen in table1, this judgment has been converted to values from 1 to 9 .

Table (1) preference values for paired scales

\begin{tabular}{lc}
\hline \multicolumn{1}{c}{ Preferences (oral judgment) } & $\begin{array}{c}\text { numerical } \\
\text { value }\end{array}$ \\
\hline Quite preferable or most important or entirely desirable & $\mathbf{9}$ \\
very strong preference or importance or desirability & $\mathbf{7}$ \\
Strong preference or importance or desirability & $\mathbf{5}$ \\
Low preference or importance or desirability & $\mathbf{3}$ \\
Same preference or importance or desirability & $\mathbf{1}$ \\
Preferences between above intervals & $\mathbf{8 , 6 , 4 , 2}$ \\
\hline
\end{tabular}

This questionnaire was distributed among the second population including the chairman, deputies and managers that are calculated relative weight of internal and external environmental factors.

\section{Phase III: Calculate the Weight of sub criteria (Level two)}

The third step was distribution and collection of questionnaire number three. It based on SAATY scale and paired comparisons too, which relative weight of components and factors identified in each group by decision maker. With explanations of the second stage, this questionnaire included 45 questions for each criteria.

\section{Phase IV: Finalizing weight of each factor}


At this stage, for determine final weight of each factor sub-criteria weights was multiplied in the weight of main criterion. Using a decision matrix, there are four main methods of extracting weights of each factor, including: method of least squares, logarithmic least squares method, eigenvector method and an approximate methods.

In this study were used Eigenvector method for deriving weighting factors in order to facilitate and expedite in calculations. In order to calculate relative weights of criteria and alternatives were used Choice Expert software. With formation of hierarchical structure and entering scores of criteria,in row and column, preferred matrices in the software, was calculated by weighting criteria to each other and final weight of alternatives. Finally, to determine the acceptability of priorities derived from the comparison matrix and consistency comparisons were used inconsistency index related to eigenvector methods, that with Expert Choice software were calculate and its value is equal $0 / 03$.

\section{FINDINGS}

Findings from the first questionnaire led to identification environmental factors in four categories: strengths, weaknesses, opportunities and threats, and findings from the two and three questionnaire led to determine weight of each criteria and sub-criteria and ultimately was determined final weight. The results are shown in Table 2.

Research findings identified rating factors related to strengths, weaknesses, opportunities and threats. Weaknesses, as the main criteria, with score $0 / 38$ had highest weight and threats with a score 0/13 had the lowest weight, also strength with $0 / 27$ \& opportunities with $0 / 22$ located in second and third place.

Also according to final weight of each components and factors related to four groups of SWOT can be said:

In group of strengths "Appropriate distribution of age and education levels in experts" ," Fitness level and education authorities with duties under supervision " and "Being codified job description, regulations and instructions for service delivery, monitoring and evaluation" respectively with score $0 / 085,0 / 080$ and $0 / 061$ had indicated highest weight.

In group of weaknesses "Weaknesses in finance management", "Weaknesses in evidence-based management" and "Weaknesses in human capital management" respectively with score $0 / 131$, 0/065 and 0/061 had indicated highest weight.

Table 2: Environmental Factors and weight \& rank of them

\begin{tabular}{|c|c|c|c|c|c|c|}
\hline \multicolumn{2}{|c|}{$\begin{array}{c}\text { Main } \\
\text { criteria } \\
\text { and their } \\
\text { weights }\end{array}$} & \multicolumn{3}{|c|}{ Sub-criteria and their weights } & $\begin{array}{c}\text { Final } \\
\text { weig } \\
\text { ht }\end{array}$ & $\begin{array}{c}\text { Pri } \\
\text { orit } \\
y\end{array}$ \\
\hline \multirow{8}{*}{ 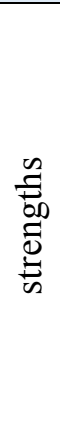 } & \multirow{8}{*}{$0 / 27$} & & Fitness level and education authorities with duties under & 0.29 & 0.08 & \\
\hline & & & supervision & 4 & 0 & 2 \\
\hline & & & Appropriate distribution of age and education levels in & 0.31 & 0.08 & \\
\hline & & & experts & 5 & 5 & 1 \\
\hline & & & Being codified job description, regulations and & 0.22 & 0.06 & \\
\hline & & S3 & $\begin{array}{l}\text { instructions for service delivery, monitoring and } \\
\text { evaluation }\end{array}$ & 6 & $\begin{array}{c}0.00 \\
1\end{array}$ & 3 \\
\hline & & S4 & Mechanized management information system & 0.08 & 0.02 & 4 \\
\hline & & S5 & Existence necessary Factors for independent financial & $\begin{array}{c}2 \\
0.05\end{array}$ & $\begin{array}{c}2 \\
0.01\end{array}$ & 5 \\
\hline
\end{tabular}




\begin{tabular}{|c|c|c|c|c|c|c|}
\hline & & S6 & Outsourcing attitudes among responsible & $\begin{array}{c}1 \\
0.03 \\
2\end{array}$ & $\begin{array}{c}4 \\
0.00 \\
9\end{array}$ & 6 \\
\hline & & & Sum & & $\begin{array}{c}0.27 \\
1\end{array}$ & \\
\hline \multirow{13}{*}{ 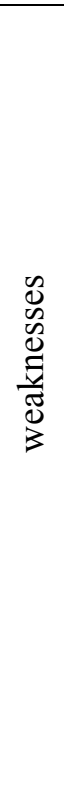 } & \multirow{13}{*}{$0 / 38$} & W1 & Weaknesses in finance management. & 0.34 & 0.13 & 1 \\
\hline & & & & 00 & 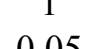 & \\
\hline & & W2 & Weaknesses in monitoring and evaluation performance & $\begin{array}{c}0.15 \\
7\end{array}$ & $\begin{array}{c}0.05 \\
9\end{array}$ & 4 \\
\hline & & W3 & Weaknesses in evidence-based management & $\begin{array}{c}0.17 \\
2\end{array}$ & 0.06 & 2 \\
\hline & & & & 0.16 & 0.06 & \\
\hline & & W4 & Weaknesses in human capital management & 2 & 1 & 3 \\
\hline & & W5 & $\begin{array}{l}\text { Weaknesses in physical resources management and } \\
\text { facilities }\end{array}$ & $\begin{array}{c}0.06 \\
1\end{array}$ & $\begin{array}{c}0.02 \\
3\end{array}$ & 5 \\
\hline & & w6 & Long work process, service delivery and low power of & 0.04 & 0.01 & 6 \\
\hline & & & system to meet new demand & 6 & 7 & 6 \\
\hline & & W7 & Multiple applications and parallel working in units & 0.03 & 0.01 & 7 \\
\hline & & We & Inonnronriate orientation health donors actions & 0.02 & 0.00 & 8 \\
\hline & & Wo & Inappropriate orientation nearth donors actions & 5 & 9 & 8 \\
\hline & & & Sum & & $\begin{array}{c}0.37 \\
8\end{array}$ & \\
\hline \multirow{9}{*}{ 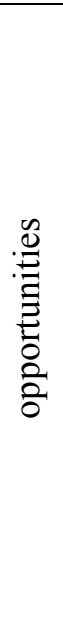 } & \multirow{9}{*}{$0 / 22$} & $\mathrm{O} 1$ & $\begin{array}{l}\text { Appropriate age pyramid and high literacy rate of } \\
\text { population }\end{array}$ & $\begin{array}{c}0.29 \\
8\end{array}$ & $\begin{array}{c}0.06 \\
6\end{array}$ & 1 \\
\hline & & 2 & Easy accecs to heolth centerc & 0.26 & 0.05 & 2 \\
\hline & & 02 & Easy access to nealth centers & 0 & 8 & 2 \\
\hline & & $\mathrm{O} 3$ & $\begin{array}{l}\text { Existence parties and social organizations, trustees, elders, } \\
\text { clergymen and their positive attitudes to health }\end{array}$ & $\begin{array}{c}0.15 \\
9\end{array}$ & $\begin{array}{c}0.03 \\
5\end{array}$ & 3 \\
\hline & & $\mathrm{O} 4$ & Existence endowed culture, philanthropists and possibility & 0.13 & 0.02 & 4 \\
\hline & & O5 & $\begin{array}{l}\text { Existence Board Trustees plan for hospital and } \\
\text { accreditation program }\end{array}$ & $\begin{array}{c}0.08 \\
6\end{array}$ & $\begin{array}{c}0.01 \\
9\end{array}$ & 5 \\
\hline & & 06 & Fxistence environmental nrotection and work safety rules & 0.06 & 0.01 & 6 \\
\hline & & & & 7 & 5 & 6 \\
\hline & & & Sum & & $\begin{array}{c}0.22 \\
2\end{array}$ & \\
\hline \multirow{10}{*}{ 菢 } & \multirow{10}{*}{$0 / 13$} & T1 & Delayed payment of insurer's obligations & $\begin{array}{c}0.14 \\
1\end{array}$ & $\begin{array}{c}0.01 \\
8\end{array}$ & 3 \\
\hline & & $\mathrm{T} 2$ & High inflation in health sector & 0.10 & 0.01 & 6 \\
\hline & & & Increased risk of addiction in vouth and low levels of life & 0.26 & 0.03 & \\
\hline & & T3 & skills & 3 & 4 & 1 \\
\hline & & T4 & Inappropriate pattern and manner in drug and food and & 0.15 & 0.02 & 2 \\
\hline & & & false beliefs and culture among people in health field & 7 & 0 & 2 \\
\hline & & T5 & Lack of full implementation of sanitary laws and & 0.10 & 0.01 & 4 \\
\hline & & & regulations by government agencies and union & 011 & 001 & \\
\hline & & T6 & $\begin{array}{l}\text { High prevalence and incidence communicable and } \\
\text { incommunicable diseases, injuries and accident }\end{array}$ & $\begin{array}{c}0.11 \\
6\end{array}$ & $\begin{array}{c}0.01 \\
5\end{array}$ & 5 \\
\hline & & $\mathrm{T} 7$ & $\begin{array}{l}\text { Low engagement and intervention of some organs in } \\
\text { affairs } \\
\text { and lack of health-oriented approach in their programs }\end{array}$ & $\begin{array}{c}0.06 \\
2\end{array}$ & $\begin{array}{c}0.00 \\
8\end{array}$ & 7 \\
\hline
\end{tabular}




\begin{tabular}{|l|llccc} 
& T8 & Non-compliance between national priority programs and & 0.02 & 0.00 & 8 \\
& regional programs & 9 & 4 & \\
& T9 & Not actual tariffs in health services & 0.01 & 0.00 & 9 \\
& & 9 & 2 & \\
& \multirow{2}{*}{ sum } & \multicolumn{3}{c}{0.12} \\
& & & 9 \\
\hline
\end{tabular}

In group of opportunities "Appropriate age pyramid and high literacy rate of population" and "Easy access to health centers" respectively with score $0 / 066$ and $0 / 058$ had indicated highest weight.

In group of threats "Increased risk of addiction in youth and low levels of life skills" and "Inappropriate pattern and manner in drug and food and false beliefs and culture among people in health field" respectively with score $0 / 034$ and 0/020 had indicated highest weight.

\section{DISCUSSION}

Contrary to previous studies in which the health status were assessed by using the SWOT matrix [12] [13] [14] [15] in this study, in addition to considering the strengths, weaknesses, opportunities and threats (matrix SWOT) has been helped AHP and fuzzy method to select real choices, that in this field can be noted the research of Josie and colleagues (2013) about rural waste management strategic planning [16], of Nazemi and colleagues (2011) about strategic planning in higher education [17], Son Il-Moon (2012) about activation strategies of occupational health and safety management system [18] and Ying \& Jinchang (2014)about evaluation of EHR in health care in China [19].

However, in the following, according to the weights of Table 2,among the environmental factors, weaknesses were rated the highest, that attention of planners and municipal health authorities require. in group of weaknesses "Weaknesses in finance management" had indicated highest weight and had earned one grade. We can say health system due to low proportion costs of health in GDP, almost 7 percent, and the high proportion households from costs of health (Out of pocket) more than half burden financing of health system, had faced challenges in funding and protecting people against damage from it, that need to revise funding for this section and raise in proportion state in paying of cost [20] [21].However, International organizations that are working to improve the health of all the world's countries (such as the World Health Organization and the World Bank) believe what most threatens health in developing countries, there are problems in the resources management, no shortage of health budget [3] [22].

In group of strengths that located in second place, "Appropriate distribution of age and education levels in experts" and "Fitness level and education authorities with duties under supervision "had highest score. Today competitive advantage of organizations is their human capital and most important asset of organization and most effective way to release bottlenecks and crises arising from economic and social development is fit and proper utilization of human capital. [23] [24] so it seems to be the center associated with young and educated staff that distributed their responsibilities appropriate to their expertise , has the shortest time possible for achieving their goals.

In group of opportunities that located in third place "Appropriate age pyramid and high literacy rate of population" had indicated highest weight that is a great opportunity for center to use the power of the people and their support for health plans.

In group of threats that located in last place "Increased risk of addiction in youth and low levels of life skills" had indicated highest weight. Drug abuse is a global issue that situation in Iran is 
epidemic; so, according to the Anti-drug Campaign, after the accident, second leading cause of death in suspicious deaths is complications of addiction. Also population pyramid Iran indicate that young people make up a large part of population (over 33 percent) so it is likely that young people because of the simple methods being orientated toward drug use, especially industrial materials. Therefore programs that awareness and inform parents in the case of warning seems to be necessary. It also can be through that necessary training to learn adolescent about the dangerous consequences of drug use through visual media and the press and strengthen religious beliefs as a preservative agent be used against the temptation of pleasure. [25] [26] From total score of environmental factors, it can be inferred that situations of organization was strengths dominance weaknesses and opportunities dominance threats; so it is recommended that organization extract strategies are needed by combining these factors with the help of various tools such as mentioned above. Also reminded that due to the higher weight of weakness between other points, planners and municipal health authorities be focus on this point.

Finally, can be say in many cases due to incorrect prioritization a lot of time and costs spent on less important matters and will not be doing any significant improvement. Therefore, it is necessary be used systematic methods such as analytic hierarchy to rank importance of each factor and determine role of it and thus there is greater confidence in the results.

\section{ACKNOWLEDGEMENT}

The authors declare that there is no conflict of interest.

\section{REFERENCES}

[1] a. razapour and s. asefzadeh, "Economic efficiency of health centers of Qazvin University of Medical Sciences:1997-98," Gilan University of Medical Sciences, pp. 63-55, 2010.

[2] k. J. Barnum H, "public hospital in developing countries," 1993.

[3] r. salehzadeh and s. ketabi, "Hospital efficiency of Qom Using DEA and AHP approach," Health Information Management, vol. 8, no. 4, pp. 479-489, 2012.

[4] h. jabari, a. janati and y. mosazadeh, "Hospital downsizing and outsourcing, using integration mechanisms," Journal of Military Medicine, vol. 15, no. 2, pp. 133-142, 2013.

[5] "European Foundation of Quality Management (EFQM). Recognition ForExcellence Information Brochure," 2004. [Online]. Available: Accessed in: Jun 12005.

[6] r. sheykhzade, "Conceptual model of performance management in mission-driven organizations," Journal of Human Resource Management, 2010.

[7] m. maleki, "Revisions in the area of common performance evaluation methods in Health Department staff.," Hakim Research Journal, 2011.

[8] e. sadat, Human Resource Management, tehran: samt Publications, 1997.

[9] X. Guo, A. Duff and M. Hair, "Service Quality Measurement in the Chinese Corporate Banking Market," International Journal of Bank Marketing, vol. 26, no. 5, pp. 305-327, 2008.

[10] s. ghaderi and h. hosseini, "Model of factors affecting the quality of banking services," Vision for Business Management, vol. 36, no. 3, pp. 89-115, 2010.

[11] s. azami, s. tabrizi and etal, "Knowledge and attitudes of managers about the accreditation of teaching hospitals, medical universities Tabriz and Ardebil," Journal of Health of Ardabil, vol. 3, no. 2, pp. 7-15, 2012.

[12] R. A. Y. M. Y. M. Ansary M, "SWOT Analysis in School of Management and Medical Information Science, Isfahan University of Medical Sciences," J Health Adm, vol. 12, no. 36, pp. 33-38, 2009. 
[13] . J. Habicht, "Estonian health system SWOT analysis," in 1st ed, Geneva, Switzerland: WHO, 2006.

[14] G. Leung, J. Johnston and B. Cowling, "Factors affecting implementation of accreditation programmes and the impact of the accreditation process on quality improvement in hospitals: a SWOT analysis," Hong Kong Medical Journal, vol. 19, no. 5, pp. 434-464, 2013.

[15] "Collaboration: a SWOT analysis of the process of conducting a review of nursing workforce policies in five European countries," Journal of Nursing Management, vol. 22, no. 4, pp. 485-498, 2014.

[16] a. gozi, m. dehghani and m. zaree, " provided Rural Waste Management Strategic Plan by A'WOT:case study(Minab City)," vol. 38, no. 4, 2013.

[17] s. nazemi, a. fatahi and h. didekhani, "Application of Combined model of SWOT and Fuzzy AHP in strategic planning at higher education, case of the faculty of economic and administration sciences," no. 2, 2011.

[18] . I.-M. Son, "A Study on Activation Strategies of Occupational Health and Safety Management System using SWOT/AHP Analysis," Journal of the Korea AcademiaIndustrial cooperation Society, vol. 13, no. 7, pp. 2895-2902, 2012.

[19] X. ,. Ying and L. Jinchang, "Evaluation of EHR in Health Care in China: Utilizing Fuzzy AHP in SWOT Analysis," Frontier and Future Development of Information Technology in Medicine and Education, vol. 269, pp. 2715-2719, 2014.

[20] N. Hassan Nejad, "Determining the Methods of Financing Health care Costs among Hospitalized Diabetic Patients in Different Types of Insurances," Hospital Journal, vol. 12, no. 3, pp. 83-90, 2012.

[21] A. Rezapour and s. Asefzadeh, "Economic efficiency in health centers of Qazvin University of Medical Sciences," Guilan University of Medical Sciences Journal, pp. 63-55, 1388.

[22] r. Salehzadeh and s. ketabi, "Evaluate the relative efficiency of hospitals in Qom Using data envelopment analysis approach and AHP processes," Health Information Management, vol. 8, no. 4, pp. 479-489, 2012.

[23] s. mardani and et al, "The relationship between Job Satisfaction and HSE Performance of Employees in a molding industry," Iran Occupational Health Journal, vol. 10, no. 6, pp. 102-91, 2013.

[24] h. shahbandarzadeh and p. bahrami, "survey empowering and motivating factors affecting the human capital in police office," Journal ofpolice management studies, vol. 8, no. 3, pp. 319-340, 2013.

[25] . K. Ahmadi and et al, "The Pattern of Drug Abuse among Soldiers," Journal of Military Medicine, vol. 15, no. 4, pp. 235-243, 2014.

[26] m. sabzi and et al, "The relationship between social control and social support as resilience against substance abuse in the boys of fathers addicted," Journal of Social Welfare, vol. 13, no. 50, pp. 27-228, 2012. 